\title{
Chemotherapy-Induced Tumor Cell Death at the Crossroads Between Immunogenicity and Immunotolerance: Focus on Acute Myeloid Leukemia
}

\begin{abstract}
Darina Ocadlikova ${ }^{1 *}$, Mariangela Lecciso $^{1}$, Alessandro Isidori ${ }^{2}$, Federica Loscocco ${ }^{2}$, Giuseppe Visani ${ }^{2}$, Sergio Amadori ${ }^{3}$, Michele Cavo ${ }^{1}$ and Antonio Curti ${ }^{1}$
\end{abstract}

\section{OPEN ACCESS}

Edited by:

Marcos De Lima

Case Western Reserve University,

United States

Reviewed by:

Benjamin Bonavida,

University of California, Los Angeles,

United States

Yona Keisari,

Tel Aviv University, Israel

*Correspondence:

Darina Ocadlikova

jennynka@seznam.cz

Specialty section

This article was submitted to

Hematologic Malignancies,

a section of the journal

Frontiers in Oncology

Received: 02 July 2019

Accepted: 18 September 2019

Published: 09 October 2019

Citation:

Ocadlikova D, Lecciso M, Isidori A

Loscocco F, Visani G, Amadori S,

Cavo M and Curti A (2019) Chemotherapy-Induced Tumor Cell

Death at the Crossroads Between

Immunogenicity and

Immunotolerance: Focus on Acute

Myeloid Leukemia.

Front. Oncol. 9:1004.

doi: 10.3389/fonc.2019.01004
${ }^{1}$ Department of Hematology and Oncology, University Hospital S. Orsola-Malpighi, Institute of Hematology "L. and A. Seràgnoli", Bologna, Italy, ${ }^{2}$ Hematology and Stem Cell Transplant Center, AORMN Hospital, Pesaro, Italy, ${ }^{3}$ Department of Medicine, Institute of Hematology, University Hospital Tor Vergata, Rome, Italy

In solid tumors and hematological malignancies, including acute myeloid leukemia, some chemotherapeutic agents, such as anthracyclines, have proven to activate an immune response via dendritic cell-based cross-priming of anti-tumor T lymphocytes. This process, known as immunogenic cell death, is characterized by a variety of tumor cell modifications, i.e., cell surface translocation of calreticulin, extracellular release of adenosine triphosphate and pro-inflammatory factors, such as high mobility group box 1 proteins. However, in addition to with immunogenic cell death, chemotherapy is known to induce inflammatory modifications within the tumor microenvironment, which may also elicit immunosuppressive pathways. In particular, DCs may be driven to acquire tolerogenic features, such as the overexpression of indoleamine 2,3-dioxygensase 1, which may ultimately hamper anti-tumor T-cells via the induction of $\mathrm{T}$ regulatory cells. The aim of this review is to summarize the current knowledge about the mechanisms and effects by which chemotherapy results in both activation and suppression of anti-tumor immune response. Indeed, a better understanding of the whole process underlying chemotherapy-induced alterations of the immunological tumor microenvironment has important clinical implications to fully exploit the immunogenic potential of anti-leukemia agents and tune their application.

Keywords: acute myeloid leukemia, immunogenic cell death, dendritic cells, $\mathbf{T}$ regulatory cells, immunosuppression

\section{ACUTE MYELOID LEUKEMIA}

Acute myeloid leukemia (AML) is a clonal disorder sprouting from a rare population of leukemic stem cells with impaired differentiation capacity into fully mature myelocytic cells. Although new and potent drugs have recently entered the clinical stage, the induction therapy of AML is still principally based on cytotoxic drugs which are able to achieve complete remission (CR) in up to $70 \%$ of adult patients $(1,2)$. However, the probability of relapse remains elevated, in particular in elderly or prognostically "high risk" patients, unless transplantation of autologous or, more importantly, allogeneic hematopoietic stem cells is performed as post-CR consolidation strategy (3). 
In the last few years, cancer immunotherapy, which is based on the ability of the immune system to recognize tumorassociated antigens (TAAs) and mediate a highly specific cytolytic response against tumor cells, is gaining much interest due to its unique characteristics, such as the absence of conventional drug resistance mechanisms and low grade of toxicity. In AML, the immunotherapy field is evolving and expanding. In this scenario, recent promising clinical results support the full development of immune-based strategies for the management of AML patients.

\section{IMMUNOGENICITY OF AML AND IMMUNOTHERAPY}

The data demonstrating increased incidence of solid tumors in immune-compromised patients, spontaneous immunebased regression of some tumors and favorable prognostic impact of tumor-infiltrating cytotoxic T lymphocytes (CTLs) or serum tumor-specific antibodies support the hypothesis that the immune system plays a very important role in tumor development, growth, and progression (4). The most clear demonstration of tumor eradication by the immune system comes from the setting of hematopoietic stem cell transplantation (SCT), where the existence of the Graft vs. Leukemia effect accounts for the prominent therapeutic activity of transplantation (5).

AML is a neoplasm with characteristics which make it suitable to elicit effective specific immune responses. Indeed, 50-90\% of cases reveal chromosomal anomalies, above all translocations, which give rise to rejected tumor antigens, namely neo-antigens, not expressed by normal cells. Moreover, leukemia cells express elevated levels of TAAs, which can be recognized by the immune system and can induce a $\mathrm{T}$ cell-targeted response. These TAAs are proteinase 3 , the receptor for hyaluronan mediated motility and Wilms tumor protein (6). Moreover, various cell types such as $\alpha \beta$ and $\gamma \delta$ T cells, and NKT and NK cells have proven to be functional against AML cells together with a series of effector molecules such as perforin and tumor necrosis factor-related apoptosis-inducing ligand, but also IFN- $\gamma$, IFN type I, and IL12 (7-9). Based on these premises, since the immune system is activated against leukemia cells, the possibility to harness immunity against AML to obtain a durable leukemia-specific immune response should not be underestimated in the clinical management of AML patients.

\section{IMMUNOGENIC CANCER CELL DEATH}

In recent years, the concept of two principal forms of cell death which can promote tolerance (e.g., apoptosis) or immunity (e.g., necrosis) was first challenged and then surpassed, and a number of factors determining whether a death is tolerogenic or immunogenic was identified (10). An example is represented by the type of cell death, induced by therapeutics such as ionizing radiations or cytotoxic chemotherapy. Selected antineoplastic agents, in particular ionizing irradiation, anthracyclines, oxaliplatin, cyclophosphamide, mitoxantrone, and others (1113), are able to induce a type of cell death which is apoptotic in morphology, but caspase-dependent and highly efficient in immune response induction without any adjuvant $(14,15)$. Such a death process, called immunogenic cell death (ICD), was introduced for the first time 10 years ago (16-20). During this process, the TAAs are released from dying tumor cells together with some factors, known as damage-associated molecular pattern molecules (DAMPs), generated in cell-stress conditions, hypoxia or nutrient depletion, which bind receptors expressed on immune cell surfaces, thus stimulating innate immune responses. In this context, specialized antigen-presenting cells, i.e., dendritic cells (DCs), play a crucial role in efficiently priming TAA-specific T cells (21). Subsequent studies have identified various mechanisms of the ICD process, and also highlighted the importance of the host capacity to detect the ICD events and induce a therapeutically relevant immune response against dying cells $(16,17,20,22,23)$.

\section{ICD EVENTS AND IMMUNE SYSTEM ACTIVATION}

ICD biology has been actively studied over the last 10 years. Very schematically, ICD is represented by the coordinated emission of a series of DAMPs (24-29), including the translocation of the endoplasmic reticulum (ER) chaperones such as calreticulin (CRT) and heat shock proteins 70 and 90 (HSP70 and 90) on cell surface, the adenosine triphosphate (ATP) active secretion, the non-histone chromatin-binding protein high mobility group box 1 (HMGB1) release from nucleus in extracellular milieu (30-37) and finally, the release of immunostimulatory cytokines, such as type I IFN (38).

In the early phase, CRT translocates from the ER to the outer leaflet of the plasma membrane, thus initiating the apoptotic caspase-dependent process. Simultaneously, the HSP70 and HSP90 bind TAAs and contribute to stimulate DC maturation. During the tardive post-apoptotic phase, pro-inflammatory factor HMGB1, which binds toll-like receptor 4 (TLR 4) on DCs, is released from the nucleus in the extracellular space. Finally, autophagy-dependent active secretion of ATP, which binds purinergic receptors (P2Rs) on DCs, promotes DC recruitment, survival and differentiation $(39,40)$.

When emitted in the correct spatiotemporal context, these DAMPs recruit DCs in the proximity of ICD and activate them to engulf TAAs. As a consequence, DCs become fully matured and competent in skewing cytokine production toward immunostimulatory cytokines, like IL-1 $\beta$, IL-12p70, and IL-6, in spite of immunosuppressive cytokines, such as IL-10 $(30,34,36)$, this process being strictly required for the adequate polarization of IFN- $\gamma$ producing $\mathrm{CD}^{+} \mathrm{T}$ cells. The activation of APCs generally proceeds in two sequential phases, i.e., recruitment of $\mathrm{T}$ cells followed by their activation into IL-17- secreting $\gamma \delta$ T cells, $\alpha \beta$ Th1 T cells (IFN- $\gamma$ secreting CD4 ${ }^{+}$T cells), and $\alpha \beta$ cytotoxic $\mathrm{T}$ cells (IFN- $\gamma$ secreting $\mathrm{CD} 8^{+} \mathrm{T}$ cells) $(27,31,34)$. The latter are not only capable of mediating direct anti-tumor effects, but also underlie the establishment of host-protective immunological memory. Importantly, CRT exposure, HMGB1 release, and ATP secretion are indispensable for ICD. Indeed, the absence of just 
one of these ICD hallmarks cancels out the efficacy of ICD in mouse model (41).

\section{Early ICD Events CRT Translocation}

CRT can be localized in the cytoplasm, on the cell membrane or in the extracellular matrix, operating in both extra and intracellular space. Inside the ER, CRT plays an essential role in the regulation of intracellular $\mathrm{Ca}^{2+}$ homeostasis and storage, thus participating in a large variety of $\mathrm{Ca}^{2+}$-dependent signal transduction mechanisms. Moreover, CRT is involved in CRT/calnexin cycles where, interacting with calnexin and 57$\mathrm{kDa}$ protein ER (ERp57), it ensures the correct folding of newly synthesized proteins and glycoproteins. In this context, CRT is fundamental also for assembly of major histocompatibility complex (MHC) molecules, which are essential for class I antigens presentation (42). Exposure to ICD inducers like anthracyclines, oxaliplatin, or ionizing radiation is able to induce translocation of CRT/ERp57 complex to the cell surface. Although the whole process underlying CRT protein exposure is far from being fully elucidated, three steps have been clearly identified: ER stress induction, apoptosis and translocation. Initially, stress response induction causes activation of reticulum PERK serin/treonin kinase which phosphorylates the eukaryotic translation initiation factor $2 \alpha$ (eIF2 $\alpha$ ) following the partial caspase- 8 activation, the caspase-8-mediated cleavage of BAP31 and structural activation of pro-apoptotic proteins BAX and BAK. Finally, the translocation process predicts exocytosis through a SNARE-dependent mechanism in which CRT and ERp57 are transported inside vesicles to the outer plasma membrane leaflet of Golgi apparatus (43, 44).

CRT exposure represents an "eat me signal" for DCs, the crucial component of immune system activation by chemotherapy (45). CRT initiates phagocytosis of apoptotic cells binding to the CD91 receptor (known as LDL-correlate receptor protein; LRP) on phagocytic cells. The presence of a CRT specific receptor on DCs and its activation are essential for immunogenicity of tumor cell death. Interestingly, CRT translocation also occurs in viable malignant cells (46), suggesting that apoptosis may not be necessarily required for CRT translocation, and that "ER stress" induction can be sufficient to promote its cell surface expression (47).

\section{HSP Exposure}

HSPs play an important role as chaperones ensuring the correct folding of newly synthesized proteins or damaged proteins as a consequence of cellular stress and preventing their aggregation. However, HSPs can have a double role based on cellular localization. In the case of HSP 90, the intracellular localization determines a cytoprotective function responsible for addressing of damaged proteins toward proteasome degradation, thus maintaining protein homeostasis (48). On the contrary, when located inside the cells, HSP70 interacts with various components of apoptotic machinery at both pre- and post-mitochondrial level, thus preventing an inappropriate ICD induction caused by stress-induced cell damage. Importantly, the HSPs can translocate to the outer plasma membrane leaflet (HSP 70) or can be released into the extracellular space (HSPs 70 and 90). HSP exposure/release from cells that underwent ER stress represents one of the distinctive factors of chemotherapy-induced ICD (48).

HSPs can potentiate immunogenicity in different ways. On one hand, when present on the cell surface of tumor cells they can improve the recognition and up-take of dying cells by DCs. On the other hand, TAAs derived from dying tumor cells can bind HSPs, thus enhancing efficient antigen presentation. HSP-antigen complex recognition is mediated by TLR4, which facilities intracellular processing and presentation of TAAs (48).

Collectively, these findings indicate that the presence of HSPs on dying tumor cells is critical for tumor cell recognition by DCs, full DC maturation and, thus, for the induction of a tumorspecific immune response.

\section{Late ICD Events}

\section{Release of HMGB1 From the Nucleus}

HMGB1 is a nuclear protein, which participates in the folding of DNA in the chromatin structure, thus influencing transcription and other nuclear functions. In contrast to histones, which are part of nucleosomes, the interaction of HMGB1 with chromatin is rather loose, which means that HMGB1 can exit from the nucleus to the cytoplasm. Importantly, HMGB1 also acts as an extracellular signal molecule, DAMP, and can be released from cells by non-canonical secretion pathways or passively released through the permeabilized plasma membrane of dead cells (49). Indeed, after cellular stress, HMGB1 translocates to cytosol and is then released to the extracellular space. When it binds to specific receptors, together with other cytokines, HMGB1 can induce myeloid DC maturation by CD40, CD54, CD80, CD83, and MHC II upregulation (20).

Under certain circumstances, cells dying by apoptosis or autophagy can release HMGB1, as observed in the case of DNA damage induced by UV radiation or platinization, where HMGB1 is sequestrated in the nucleus and the ICD inducers, such as anthracyclines, and stimulate HMGB1 release in the late phase of apoptosis (20). HMGB1 released in the extracellular space binds mainly the TLR4 present on DCs, thus facilitating TAA processing and presentation through the inhibition of phagosome and lysosome fusion, and the prevention of early degradation and by allowing their transport to effector immune cells (48). Moreover, it has been demonstrated that HMGB1 released during tumor cell necrosis induces not only DC maturation, but also secretion of IL-12 by DCs and IFN- $\gamma$ by $\mathrm{T}$ cells acting as a potent stimulus for polarization of Th1 response (20).

\section{ATP Extracellular Release}

One of the most distinctive features of ICD is represented by the active extracellular release of ATP from dying cells during the tardive phase of apoptosis. Normally located inside the cells, ATP is considered the most important factor for bioenergetics, connecting anabolism and catabolism, with a well-established crucial role in some important processes, such as cellular motility, phosphorylation, and active transport. By specifically testing which of the P2Rs is involved, as well as the type or the optimal concentration of released nucleotides within the extracellular 
environment, various and seminal studies demonstrated the role of extracellular nucleotides in the regulation of cell proliferation, migration, and death $(50,51)$.

While different mechanisms of ATP release are known, the elevated release of ATP during ICD induced by chemotherapy principally depends on the induction of the autophagy process. Autophagy is a multistep process that involves cytoplasmic material sequestration within double-membraned organelles, autophagosomes, and their fusion with lysosomes (52). Importantly, besides its role as a DAMP molecule, extracellular ATP represents a strong "find me" signal which facilitates DC recruitment in sites of massive apoptosis (53). $\mathrm{DC}$ recruitment in tumor sites is mediated by $\mathrm{P} 2 \mathrm{Y} 2$ receptors (54), whereas activation of P2Y11 receptors on monocytes and DCs induces their maturation (55). Once recruited, naive immune cells need activation signals to increase their anti-tumoral activity. It has recently been demonstrated that P2XRs are essential for the immune response induced by chemotherapy. ATP released from dying cells binds to the P2X7 receptor present on DCs, thus determining assembly and activation of inflammasome NOD-like Receptor protein 3 (NLRP3)/ASC/caspasi-1 driving the IL-1 $\beta$ secretion. The IL-1 $\beta$ is fundamental for adequate recruitment of $\gamma \delta \mathrm{T}$ lymphocytes secreting IL-17 and cytotoxic $\mathrm{CD}^{+} \mathrm{IFN}-\gamma^{+}$tumor-specific T lymphocyte generation $(56,57)$.

\section{ICD IN SOLID TUMORS AND LEUKEMIAS}

Recent data support the role of chemotherapy in activating the immune response both in solid tumors $(9,11,12,44,58)$ and, recently, in leukemias $(34,47,59-62)$, with important therapeutical implications.

For a long time, the immune system was considered as a passive bystander of cancers, until the antineoplastic potential of new drugs in immunodeficient murine models was tested. Accumulating preclinical evidence has indicated that murine tumors respond more efficiently to therapies in immunocompetent individuals than in immunodeficient hosts $(63,64)$, suggesting an important role of the immune system mediating the chemotherapy effects. Several anticancer agents, for example anthracyclines in colorectal cancer (9), fibrosarcomas (57), and methylcholanthrene-induced tumors (65), cyclophosphamide in mesotheliomas (66), oxaliplatin in colorectal carcinomas and fibrosarcomas $(12,31)$, and cisplatin in combination with digoxin in fibrosarcomas (67) were tested and proven to activate the immune system, which ultimately and crucially contributes to the clinical response of cancers to chemotherapy treatment.

Regarding chemotherapeutic drugs, it is very important to differentiate between the direct immunogenic effects that such therapeutic regimens exert on tumor cells, and the capacity of chemotherapy-treated tumor cells to interact with the host immune system, resulting in reactivation of immune effectors, or in relief of immune-suppressive mechanisms. Three principal ways in which antineoplastic agents may stimulate the immune system were defined by Zitvogel et al.: increasing the antigenicity of cancer cells (increased TAA expression or presentation) (i); increasing the immunogenicity of cancer cells (DAMP production and release) (ii) and increasing the susceptibility of cancer cells (better recognition and killing of cancer cells by immune effectors) (iii) (68). As for the enhancement of antigenicity, cyclophosphamide, oxaliplatin and $\gamma$ irradiation have been shown to increase MHC I molecule expression by cancer cells $(69,70)$, whereas $\gamma$ irradiation, 5fluorouracil or vemurafenib increased TAA expression (69, 71,72 ). Regarding immunogenicity, anthracyclines, oxaliplatin, mafosfamide, bortezomib, and some other types of chemotherapy agents are effective in inducing CRT and HSP exposure $(11,12,32,47,59,61)$, as well as ATP secretion (31, 52, $55)$ and HMGB1 release $(12,73)$ from various tumor cells including leukemias. Finally, to increase the susceptibility of cancer cells, different anticancer agents including anthracyclines have been shown to sensitize murine tumor cells to the cytotoxic function of CTLs (74). Moreover, other pieces of evidence indicate that chemotherapy favors breast cancer cell infiltration by myeloid and granzyme B-expressing cells, while increasing the intra-tumoral $\mathrm{CD}^{+}$and $\mathrm{CD}^{+}{ }^{+} \mathrm{T}$ cell ratio (75). Taken together, accumulating evidence suggests that, in some settings, tumor-specific immune responses induced during chemotherapy drive the destiny of cancer patients $(76,77)$.

For hematological malignancies, recent studies have demonstrated that anthracyclines trigger ICD in vitro and in murine models (78) including AML (34, 47). In particular, in AML patients, following anthracycline administration, CRT translocates from the nucleus to the leukemia cell surface. Indeed, Fredly et al. has demonstrated that CRT is exposed by apoptotic primary human AML cells in $65 \%$ of tested patients and that, in vitro, cultured AML cells showed spontaneous release of HSP70 and 90 (62). Of note, similarly to solid tumors, including neuroblastoma, non-small cell lung carcinoma, ovarian cancer, and colorectal carcinoma, where CRT exposure has been shown to be an important prognostic factor (79-81), CRT exposure by AML cells has been recently correlated by Fucikova et al. with a strong anticancer immune response, improving the clinical outcome of AML patients $(59,60)$. Surprisingly, these authors have found that DAMP emission from AML may also be chemotherapy-independent. In particular, $82 \%$ of AML patients exhibited positivity for CRT expression prior to treatment and a similar pattern was observed also for HSP exposure and HMGB1 release, thus suggesting that DAMP production may represent an intrinsic feature of some types of AML, which make them more prone to interact with the immune system. Indeed, CRT exposure was associated with enhanced anti-leukemia immune response and better prognosis. Transcriptional and phenotyping signature analysis in patients with AML has revealed robust vs. weak CRT exposure on blasts. Moreover, AML patients are prognostically divided into two groups based on the median percentage of circulating ecto-CRT, HSP70, or HSP90 positive cells, thus revealing that ICD-associated DAMPs correlate with improved disease outcome (60). CRT exposure on malignant blasts predicts a cellular anticancer immune response in patients with AML (61). 
TABLE 1 | Inhibitory pathways in AML.

\begin{tabular}{|c|c|c|c|}
\hline $\begin{array}{l}\text { Inhibitory } \\
\text { pathway/check } \\
\text { point }\end{array}$ & Physiological role & Role in AML & Clinical trials in AML \\
\hline PD-1/PD-L1 axes & $\begin{array}{l}\text { PD-1-receptor of negative co-stimulation. } \\
\text { Ligands: PD-L1 and PD-L2. } \\
\text { PD-1/PD-L1 axes-control of normal immune } \\
\text { responses, involved in periphery tolerance, } \\
\text { autoimmunity regulation, allergy, infections, and } \\
\text { antitumor immunity (87). }\end{array}$ & $\begin{array}{l}\text { PD-1/PD-L signaling-dampening of } \\
\text { anti-leukemic immunity in AML. } \\
\text { PD-L1 and PD-L2 expression on human AML } \\
\text { cells at diagnosis and relapse (88). } \\
\text { Blocking of PD-1/PD-L1 axis - increase of } \\
\text { anti-leukemia immune response and prevention of } \\
\text { AML progression in murine model }(83,84,89) \text {. }\end{array}$ & $\begin{array}{l}\text { 1. Anti-PD-1 } \\
\text { Nivolumab: NCT02275533, } \\
\text { NCT02397720, } \\
\text { NCT02532231, NCT03092674, } \\
\text { NCT02464657, } \\
\text { NCT02275533, NCT03066648 } \\
\text { Pembrolizumab: NCT02708641, } \\
\text { NCT02845297, NCT02996474, } \\
\text { NCT02771197, NCT02768792 } \\
\text { Avelumab: } \\
\text { NCT02953561 } \\
\text { 2. Anti-PD-L1 } \\
\text { Durvalumab: } \\
\text { NCT02775903 } \\
\text { Atezolizumab: } \\
\text { NCT02892318, NCT03154827 }\end{array}$ \\
\hline CTLA-4 & $\begin{array}{l}\text { CTLA-4-receptor of negative co-stimulation. } \\
\text { Ligands: CD80 and CD86. } \\
\text { CTLA-4/CD80/CD86 pathway-regulation of T } \\
\text { cell response (83). }\end{array}$ & $\begin{array}{l}\text { CTLA-4/CD80/CD86-hampering T cell immunity } \\
\text { against hematological malignancies (83) and } \\
\text { modulating immune responses in AML (90). } \\
\text { Blocking of CTLA-4 pathway-increase of } \\
\text { anti-leukemia T-cell immune response translated in } \\
\text { prolonged tumor regression }(91,92) \text {. }\end{array}$ & $\begin{array}{l}\text { 1. Anti-CTLA-4 } \\
\text { Ipilimumab: } \\
\text { NCT00039091, } \\
\text { NCT02890329, NCT02397720 }\end{array}$ \\
\hline CD200R/CD200 & $\begin{array}{l}\text { CD200R-inhibitory receptor. } \\
\text { Ligand: CD200. } \\
\text { CD200-CD200R signaling - down-regulation of } \\
\text { immune responses preventing inflammation and } \\
\text { immune pathology (83). }\end{array}$ & $\begin{array}{l}\text { CD200R/CD200-immunosuppressive signal } \\
\text { transmission, macrophages inhibition, Tregs } \\
\text { induction and tumor-specific T cells inhibition (93). } \\
\text { Expression of CD200 on human AML cells } \\
\text { (94)-worse overall survival of some AML } \\
\text { subsets (83). } \\
\text { Blocking of CD200-enhanced cytotoxicity of NK } \\
\text { cells, restored proliferative capacity of T cells, } \\
\text { dampens tumor-reactive immune responses (95), } \\
\text { but also favors tumor progression due to enhanced } \\
\text { pro-tumorigenic inflammation (96). }\end{array}$ & $\begin{array}{l}\text { 1. Anti-CD200 } \\
\text { Samalizumab: } \\
\text { NCT03013998 }\end{array}$ \\
\hline Lag-3 & $\begin{array}{l}\text { Lag-3 receptor of negative co-stimulation. } \\
\text { Ligand: } \mathbf{M H C ~ I I . ~} \\
\text { Lag-3/MHCII signaling - tolerance maintenance } \\
(83,97) \text {. }\end{array}$ & $\begin{array}{l}\text { Lag-3 signaling-suppression of CTL activity in } \\
\text { tumors (97, 98). } \\
\text { Blocking of PD-L1, CTLA-4 and } \\
\text { Lag-3-effective and enduring immunotherapy for } \\
\text { disseminated leukemia in murine model (98). }\end{array}$ & To date - no clinical trials available \\
\hline Tim-3 & $\begin{array}{l}\text { Tim-3-receptor of negative co-stimulation. } \\
\text { Ligands: gal-9/HMGB1/phosphatidyl serin. } \\
\text { Tim-3/gal-9 signaling-regulation of T-cell } \\
\text { tolerance (83). }\end{array}$ & $\begin{array}{l}\text { Tim-3 released by AML-reduce ability of T cells } \\
\text { to secrete IL-2 required for NK and CTLs } \\
\text { activation (99). } \\
\text { TIM-3 and PD-1 co-expression on T cells was } \\
\text { associated with AML progression in mouse and } \\
\text { human (7) and with relapse in AML patients after } \\
\text { allo-SCT (100). } \\
\text { TIM-3-overexpression on AML (stem) cells (101) } \\
\text { and T cells of newly diagnosed AML -(102). } \\
\text { Blocking of TIM-3 and PD-1 - reduced tumor } \\
\text { burden and improved survival in AML murine } \\
\text { model (7). }\end{array}$ & $\begin{array}{l}\text { 1. AntiPD-1 + TIM-3 } \\
\text { PDR001+MBG453+ Decitabine: } \\
\text { NCT03066648 }\end{array}$ \\
\hline IDO and Tregs & $\begin{array}{l}\text { IDO -immunosuppressive and tolerogenic } \\
\text { enzyme responsible for tryptophan degradation in } \\
\text { kynurenines with subsequent T cell inhibition and } \\
\text { Tregs expansion. } \\
\text { Tregs - role in maternal tolerance, autoimmune } \\
\text { disease regulation, suppression of transplant } \\
\text { rejection (85). }\end{array}$ & $\begin{array}{l}\text { IDO signaling-Tregs induced by IDO-expressing } \\
\text { leukemic DCs impair leukemia-specific CTL (103). } \\
\text { Increased IDO activity-lower CR rates and } \\
\text { shorter OS in AML (103-105). } \\
\text { Blocking of IDO-effective immune response in } \\
\text { AML in vitro (103-106). }\end{array}$ & $\begin{array}{l}\text { 1. Anti-IDO } \\
\text { Epacadostat: } \\
\text { NCT03444649 }\end{array}$ \\
\hline
\end{tabular}

Different inhibitory pathways and their role in both physiological and AML contexts are correlated with clinical trials ongoing for specific pathways. 


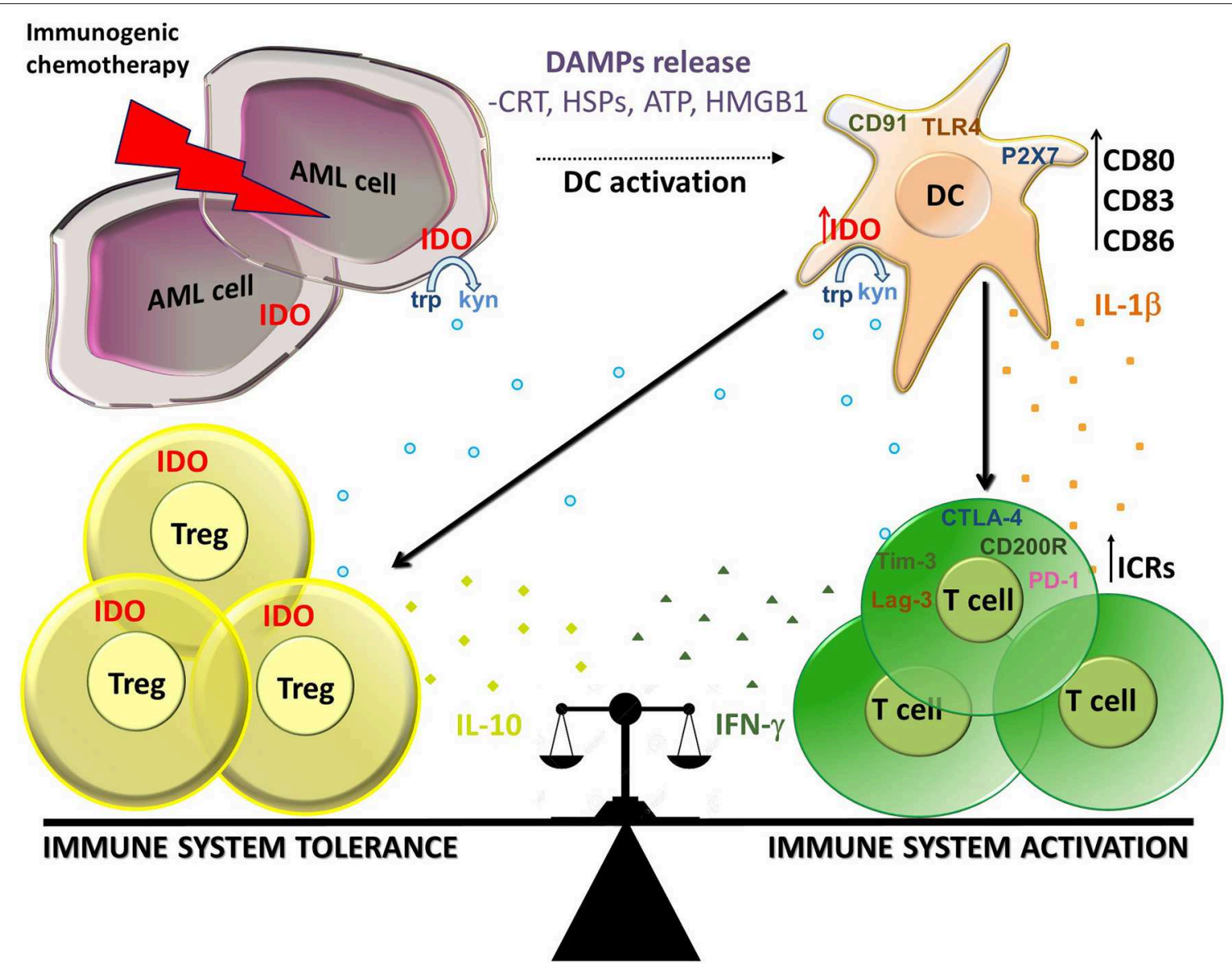

FIGURE 1 | Balance between immune activation and tolerance during ICD in AML. Immunogenic chemotherapy causes the release of DAMPs (CRT, HSPs, ATP, and HMGB1) which bind to receptors on DCs as CD91, TLR4, and P2X7. DCs up-regulate maturation markers (CD80, CD86, and CD83) and produce IL-1 $\beta$ resulting in activation of T cells producing IFN- $\gamma$ At the same time, DCs up-regulate IDO1 which is responsible for the production of kynurenines which in turn stimulate induction of Tregs producing IL-10 and inhibit effector T cells. IDO1 is expressed also on AML cells and Treg cells, thus participating to the suppressive local milleu. Immune check points receptors (ICRs) as PD-1, Tim-3, Lag-3, CD200R, and CTLA-4 can contribute to the cell composition of tumor microenvironment. In this context, IDO1 seems to play a key role in the balance between immune system activation and tolerance in AML during ICD.

\section{MECHANISMS OF IMMUNOLOGIC TOLERANCE IN AML}

Along with the well-known cell-intrinsic mechanisms by which leukemic cells can develop drug resistance, which leads to enhanced proliferation and survival, the role of cellextrinsic factors, partly derived from AML bone marrow, the immunosuppressive microenvironment has recently been investigated (82). It is known that both the innate and adaptive immune systems are deeply affected and profoundly deregulated by the interaction with leukemia cells. This happens as a result of several different immunosuppressive mechanisms, which, in turn, may lead to the escape of leukemia cells from the natural immunological control (82). Many of these regulatory mechanisms seem to be shared by solid tumors and hematology neoplasms including over-expression of inhibitory check-point receptors on $\mathrm{T}$ cells and their ligands on $\mathrm{AML}$ cells or DCs such as PD-1/PD-L1, CTLA-4/CD80/CD86, Tim3/galectine-9 (gal-9), and Lag-3/MHCII, enzymes as IDO and induction of immunoregulatory populations expansion as Tregs (83-85). The most known suppressive mechanism in AML is the up-regulation of IDO1 expression on leukemia cells. IDO1 is responsible for catalyzing the initial rate-limiting step of tryptophan degradation resulting in increased final product kynurenines. The kynurenines have suppressive properties and increase the conversion of $\mathrm{CD}^{+} 25^{-} \mathrm{T}$ cells into Tregs. In addition, their suppressive effect relies on the fact that they can reduce the activity of NK cells, DCs or proliferating T cells, in response to inflammation or infection $(85,86)$. The most known inhibitory pathways in AML are reported in Table $\mathbf{1 .}$

\section{TOLEROGENIC MECHANISMS DURING ICD}

In the ICD scenario, some recent reports indicate that, along with the activation of the immune system, a wide variety of tolerogenic mechanisms is also induced, mostly resulting in Tregs induction $(53,107,108)$. In particular, Tregs induction after immunogenic 
chemotherapy was observed in some solid tumors. Bugaut et al. demonstrated that bleomycin, an anti-tumor antibiotic glycopeptide produced by bacterium Streptomyces and used for the treatment of cancer testis and Hodgkin disease, induces both ICD resulting in anti-tumor $\mathrm{CD}^{+} \mathrm{T}$ cell response and Tregs accumulation in vivo. Specifically, bleomycin induces expansion of Foxp $3^{+}$Tregs via its capacity to induce transforming growth factor beta (TGF- $\beta$ ) secretion by tumor cells. Accordingly, Tregs or TGF- $\beta$ depletion dramatically potentiates the antitumor effect of bleomycin. Based on these premises, it is conceivable that in order to fully exploit the activatory capacity of immune response by immunogenic chemotherapy, it may be fundamental to concomitantly block chemotherapy-driven Tregs induction.

Similarly to solid tumors, also in AML it is well-known that inducing a suppressive microenvironment by expanding Tregs may hamper the anti-leukemia immune response (103, 109). Interestingly, early lymphocyte recovery in 20 patients undergoing induction chemotherapy for newly diagnosed AML indicated that recovering $\mathrm{T}$ cells were predominantly activated Tregs with suppressive activity. Despite an initial burst of thymopoiesis, most recovering Tregs were of peripheral origin and showed marked oligoclonal skewing, suggesting that their peripheral expansion was antigen-driven (108). Wang et al. too demonstrated a rapid turnover of Tregs in AML patients after chemotherapy compared to healthy controls (110). Together, these findings suggest an important role of Tregs induction after chemotherapy in AML.

We recently investigated the mechanisms underlying the effects of chemotherapy on Tregs induction. In particular, we focused on the tolerogenic role of leukemia-infiltrating DCs after chemotherapy. Our in vitro and in vivo data demonstrate that during ICD a population of DCs expressing IDO1 is responsible for the induction of Tregs (106). In particular, we demonstrated that ATP released from chemotherapy-treated AML cells is responsible for IDO1 up-regulation on DCs through the P2X7 receptor and consequent Tregs enrichment, resulting in the establishment of an immune suppressive microenvironment. Moreover, the analysis of the T-cell composition emerging in AML patients after induction chemotherapy revealed an enrichment and activation of the most suppressive Tregssubpopulation expressing FOXP-3, CTLA-4, CD39, PD-1, and Ki-67 (106). These results demonstrated that ATP released from chemotherapy-treated dying leukemic cells during ICD has a role in the induction of the immune suppressive microenvironment, which comprises Tregs and IDO1-expressing DCs (106).

Taken together, these findings suggest that IDO and related downstream pathways resulting in Tregs induction may play an important regulatory role in the choice between tolerance or immunity in response to dying tumor cells (Figure 1) and are in line with other recent studies which use preclinical

\section{REFERENCES}

1. Döhner H, Estey E, Grimwade D, Amadori S, Appelbaum FR, Büchner $\mathrm{T}$, et al. Diagnosis and management of AML in adults: 2017 ELN models of self-tolerance and autoimmunity (85). In this scenario, chemotherapy-induced ICD can prompt both immune tolerance and activation through the same mechanisms, and the balance between these phenomena can be fundamental for the final immune system response.

\section{CONCLUDING REMARKS}

Some antineoplastic agents are capable of activating the immune system through the release of inflammatory signals from dying tumor cells. However, recent evidence indicates that chemotherapy may also provide the tumor microenvironment with a number of tolerogenic signals, mainly resulting in Tregs induction, which negatively influence immune response activation. Interestingly, the same mechanisms leading to immune activation are suggested to be also responsible for tolerance induction. Then, to fully exploit the immunogenic potential of chemotherapy, it is necessary to concomitantly act by inhibiting tolerance induction. Indeed, early clinical studies are testing the safety and early efficacy of new immunological agents contrasting tolerogenic mechanisms, such as IDO1 and immune checkpoint inhibitors, in combination with immunogenic chemotherapy.

Although this dual process is relevant in many tumors, it is particularly important in the setting of AML, where chemotherapy still constitutes the most powerful and curative therapeutical tool for most patients. For these reasons, in the AML field these studies will help in better understanding the biology of ICD, including the critical balance between activation and tolerance, thus providing the rationale for moving another step forward for an integrated immunological approach to AML therapy.

\section{AUTHOR CONTRIBUTIONS}

DO wrote and revised the manuscript and was the major contributor. ML wrote and revised sections of the manuscript. FL collected the related papers. SA, GV, MC, and AI participated in the design of the review and helped to draft and revise the manuscript. AC wrote sections of the manuscript, participated in the design of the review, and helped to draft and revise the manuscript. All authors read and approved the final manuscript.

\section{FUNDING}

This study was supported by AIRC (Associazione Italiana per la Ricerca sul Cancro) 2017 IG20654, FATRO/Foundation Corrado and Bruno Maria Zaini-Bologna, Fabbri1905, Bologna AIL (Associazione Italiana contro le Leucemie)/Section of Bologna and AIL Pesaro Onlus. 
3. Burnett A, Wetzler M, Löwenberg B. Therapeutic advances in acute myeloid leukemia. J Clin Oncol. (2011) 29:487-94. doi: 10.1200/JCO.2010.30.1820

4. Gonzalez H, Hagerling C, Werb Z. Roles of the immune system in cancer: from tumor initiation to metastatic progression. Genes Dev. (2018) 32:126784. doi: 10.1101/gad.314617.118

5. Dickinson AM, Norden J, Li S, Hromadnikova I, Schmid C, Schmetzer $\mathrm{H}$, et al. Graft-versus-leukemia effect following hematopoietic stem cell transplantation for leukemia. Front Immunol 8:496. doi: 10.3389/fimmu.2017.00496

6. Anguille S, Van Tendeloo VF, Berneman ZN. Leukemia-associated antigens and their relevance to the immunotherapy of acute myeloid leukemia. Leukemia. (2012) 26:2186-96. doi: 10.1038/leu.2012.145

7. Zhou Q, Munger ME, Veenstra RG, Weigel BJ, Hirashima M, Munn DH, et al. Coexpression of Tim-3 and PD-1 identifies a CD8 ${ }^{+}$T-cell exhaustion phenotype in mice with disseminated acute myelogenous leukemia. Blood. (2011) 117:4501-10. doi: 10.1182/blood-2010-10-310425

8. Acheampong DO, Adokoh CK, Asante DB, Asiamah EA, Barnie PA, Bonsu DOM, et al. Immunotherapy for acute myeloid leukemia (AML): a potent alternative therapy. Biomed Pharmacother. (2018) 97:225-32. doi: 10.1016/j.biopha.2017.10.100

9. Wang YJ, Fletcher R, Yu J, Zhang L. Immunogenic effects of chemotherapy-induced tumor cell death. Genes Dis. (2018) 5:194-203. doi: 10.1016/j.gendis.2018.05.003

10. Ferguson TA, Choi J, Green DR. Armed response: how dying cells influence T-cell functions. Immunol Rev. (2011) 241:77-88. doi: 10.1111/j.1600-065X.2011.01006.x

11. Schiavoni G, Sistigu A, Valentini M, Mattei F, Sestili P, Spadaro F, et al. Cyclophosphamide synergizes with type I interferons through systemic dendritic cell reactivation and induction of immunogenic tumor apoptosis. Cancer Res. (2011) 71:768-78. doi: 10.1158/0008-5472.CAN-10-2788

12. Tesniere A, Schlemmer F, Boige V, Kepp O, Martins I, Ghiringhelli F, et al. Immunogenic death of colon cancer cells treated with oxaliplatin. Oncogene. (2010) 29:482-91. doi: 10.1038/onc.2009.356

13. Inoue $\mathrm{H}$, Tani $\mathrm{K}$. Multimodal immunogenic cancer cell death as a consequence of anticancer cytotoxic treatments. Cell Death Differ. (2014) 21:39-49. doi: 10.1038/cdd.2013.84

14. Galluzzi L, Maiuri MC, Vitale I, Zischka H, Castedo M, Zitvogel L, et al. Cell death modalities: classification and pathophysiological implications. Cell Death Differ. (2007) 14:1237-43. doi: 10.1038/sj.cdd.4402148

15. Casares N, Pequignot MO, Tesniere A, Ghiringhelli F, Roux S, Chaput N, et al. Caspase-dependent immunogenicity of doxorubicin-induced tumor cell death. J Exp Med. (2005) 202:1691-701. doi: 10.1084/jem.20050915

16. Kroemer G, Galluzzi L, Kepp O, Zitvogel L. Immunogenic cell death in cancer therapy. Annu Rev Immunol. (2013) 31:51-72. doi: 10.1146/annurev-immunol-032712-100008

17. Kepp O, Senovilla L, Vitale I, Vacchelli E, Adjemian S, Agostinis P, et al. Consensus guidelines for the detection of immunogenic cell death. Oncoimmunology. (2014) 3:e955691. doi: 10.4161/21624011.2014.955691

18. Garg AD, Agostinis P. ER stress, autophagy and immunogenic cell death in photodynamic therapy-induced anti-cancer immune responses. Photochem Photobiol Sci. (2014) 13:474-87. doi: 10.1039/C3PP50333J

19. Galluzzi L, Vacchelli E, Bravo-San Pedro JM, Buqué A, Senovilla L, Baracco EE, et al. Classification of current anticancer immunotherapies. Oncotarget. (2014) 5:12472-508. doi: 10.18632/oncotarget.2998

20. Krysko DV, Garg AD, Kaczmarek A, Krysko O, Agostinis P, Vandenabeele P. Immunogenic cell death and DAMPs in cancer therapy. Nat Rev Cancer. (2012) 12:860-75. doi: 10.1038/nrc3380

21. Chen DS, Mellman I. Oncology meets immunology: the cancer-immunity cycle. Immunity. (2013) 39:1-10. doi: 10.1016/j.immuni.2013.07.012

22. Kepp O, Galluzzi L, Martins I, Schlemmer F, Adjemian S, Michaud $\mathrm{M}$, et al. Molecular determinants of immunogenic cell death elicited by anticancer chemotherapy. Cancer Metastasis Rev. (2011) 30:61-9. doi: 10.1007/s10555-011-9273-4

23. Cirone M, Di Renzo L, Lotti LV, Conte V, Trivedi P, Santarelli R, et al. Activation of dendritic cells by tumor cell death. Oncoimmunology. (2012) 1:1218-9. doi: 10.4161/onci.20428
24. Brenner C, Galluzzi L, Kepp O, Kroemer G. Decoding cell death signals in liver inflammation. J Hepatol. (2013) 59:583-94. doi: 10.1016/j.jhep.2013.03.033

25. Galluzzi L, Kepp O, Kroemer G. Mitochondria: master regulators of danger signalling. Nat Rev Mol Cell Biol. (2012) 13:780-8. doi: 10.1038/nrm3479

26. Garg AD, Martin S, Golab J, Agostinis P. Danger signalling during cancer cell death: origins, plasticity and regulation. Cell Death Differ. (2014) 21:26-38. doi: $10.1038 /$ cdd. 2013.48

27. Garg AD, Dudek AM, Agostinis P. Cancer immunogenicity, danger signals, and DAMPs: what, when, and how? Biofactors. (2013) 39:355-67. doi: 10.1002/biof.1125

28. Garg AD, Krysko DV, Vandenabeele P, Agostinis P. DAMPs and PDTmediated photo-oxidative stress: exploring the unknown. Photochem Photobiol Sci. (2011) 10:670-80. doi: 10.1039/c0pp00294a

29. Garg AD, Nowis D, Golab J, Vandenabeele P, Krysko DV, Agostinis P. Immunogenic cell death, DAMPs and anticancer therapeutics: an emerging amalgamation. Biochim Biophys Acta. (2010) 1805:53-71. doi: 10.1016/j.bbcan.2009.08.003

30. Apetoh L, Ghiringhelli F, Tesniere A, Obeid M, Ortiz C, Criollo A, et al. Toll-like receptor 4-dependent contribution of the immune system to anticancer chemotherapy and radiotherapy. Nat Med. (2007) 13:1050-9. doi: $10.1038 / \mathrm{nm} 1622$

31. Michaud M, Martins I, Sukkurwala AQ, Adjemian S, Ma Y, Pellegatti $\mathrm{P}$, et al. Autophagy-dependent anticancer immune responses induced by chemotherapeutic agents in mice. Science. (2011) 334:1573-7. doi: $10.1126 /$ science. 1208347

32. Spisek R, Charalambous A, Mazumder A, Vesole DH, Jagannath S, Dhodapkar MV. Bortezomib enhances dendritic cell (DC)-mediated induction of immunity to human myeloma via exposure of cell surface heat shock protein 90 on dying tumor cells: therapeutic implications. Blood. (2007) 109:4839-45. doi: 10.1182/blood-2006-10-054221

33. Garg AD, Dudek AM, Ferreira GB, Verfaillie T, Vandenabeele P, Krysko DV, et al. ROS-induced autophagy in cancer cells assists in evasion from determinants of immunogenic cell death. Autophagy. (2013) 9:1292-307. doi: 10.4161/auto.25399

34. Fucikova J, Kralikova P, Fialova A, Brtnicky T, Rob L, Bartunkova $\mathrm{J}$, et al. Human tumor cells killed by anthracyclines induce a tumor-specific immune response. Cancer Res. (2011) 71:4821-33. doi: 10.1158/0008-5472.CAN-11-0950

35. Ghiringhelli F. Activation of the NLRP3 inflammasome in dendritic cells induces IL-1beta-dependent adaptive immunity against tumors. Nat Med. (2009) 15:1170-8. doi: 10.1038/nm.2028

36. Obeid M. Calreticulin exposure dictates the immunogenicity of cancer cell death. Nat Med. (2007) 13:54-61. doi: 10.1038/nm1523

37. Fucikova J, Moserova I, Truxova I, Hermanova I, Vancurova I, Partlova S, et al. High hydrostatic pressure induces immunogenic cell death in human tumor cells. Int J Cancer. (2014) 135:1165-77. doi: 10.1002/ijc.28766

38. Sistigu A, Yamazaki T, Vacchelli E, Chaba K, Enot DP, Adam J, et al. Cancer cell-autonomous contribution of type I interferon signaling to the efficacy of chemotherapy. Nat Med. (2014) 20:1301-9. doi: 10.1038/nm.3708

39. Vacchelli E. Trial watch: chemotherapy with immunogenic cell death inducers. Oncoimmunology. (2012) 1:179-88. doi: 10.4161/onci.1.2.19026

40. Haynes NM. Immunogenic anti-cancer chemotherapy as an emerging concept. Curr Opin Immunol. (2008) 20:545-57. doi: 10.1016/j.coi.2008.05.008

41. Martins I, Michaud M, Sukkurwala AQ, Adjemian S, Ma Y, Shen $S$, et al. Premortem autophagy determines the immunogenicity of chemotherapy-induced cancer cell death. Autophagy. (2012) 8:413-5. doi: 10.4161/auto.19009

42. Wijeyesakere SJ, Gagnon JK, Arora K, Brooks CL, Raghavan M. Regulation of calreticulin-major histocompatibility complex (MHC) class I interactions by ATP. Proc Natl Acad Sci USA. (2015) 112:E5608-17. doi: $10.1073 /$ pnas. 1510132112

43. Wang WA, Groenendyk J, Michalak M. Calreticulin signaling in health and disease. Int J Biochem Cell Biol. (2012) 44:842-6. doi: 10.1016/j.biocel.2012.02.009 
44. Panaretakis T. Mechanism of pre-apoptotic calreticulin exposure in immunogenic cell death. EMBO J. (2009) 28:578-90. doi: 10.1038/emboj.2009.1

45. Krysko DV, Ravichandran KS, Vandenabeele P. Macrophages regulate the clearance of living cells by calreticulin. Nat Commun. (2018) 9:4644. doi: 10.1038/s41467-018-06807-9

46. Chao MP, Jaiswal S, Weissman-Tsukamoto R, Alizadeh AA, Gentles AJ, Volkmer J, et al. Calreticulin is the dominant pro-phagocytic signal on multiple human cancers and is counterbalanced by CD47. Sci Transl Med. (2010) 2:63ra94. doi: 10.1126/scitranslmed.3001375

47. Chen X, Fosco D, Kline DE, Kline J. Calreticulin promotes immunity and type I interferon-dependent survival in mice with acute myeloid leukemia. Oncoimmunology. (2017) 6:e1278332. doi: 10.1080/2162402X.2016.1278332

48. Montico B, Nigro A, Casolaro V, Dal Col J. Immunogenic apoptosis as a novel tool for anticancer vaccine development. Int J Mol Sci. (2018) 19:E594. doi: 10.3390/ijms19020594

49. Liu P, Zhao L, Loos F, Iribarren K, Lachkar S, Zhou H, et al. Identification of pharmacological agents that induce HMGB1 release. Sci Rep. (2017) 7:14915. doi: 10.1038/s41598-017-14848-1

50. Dou L, Chen YF, Cowan PJ, Chen XP. Extracellular ATP signaling and clinical relevance. Clin Immunol. (2018) 188:67-73. doi: 10.1016/j.clim.2017.12.006

51. Bonora M, Patergnani S, Rimessi A, De Marchi E, Suski JM, Bononi A, et al. ATP synthesis and storage. Purinergic Signal. (2012) 8:343-57. doi: $10.1007 / \mathrm{s} 11302-012-9305-8$

52. Martins I. Molecular mechanisms of ATP secretion during immunogenic cell death. Cell Death Diff. (2014) 21:79-91. doi: 10.1038/cdd.2013.75

53. Krysko O. Many faces of DAMPs in cancer therapy. Cell Death Dis. (2013) 4:e631. doi: 10.1038/cddis.2013.156

54. Ma Y. Anticancer chemotherapy-induced intratumoral recruitment and differentiation of antigen-presenting cells. Immunity. (2013) 38:729-41. doi: 10.1016/j.immuni.2013.03.003

55. Ma Y, Adjemian S, Yang H, Catani JP, Hannani D, Martins I, et al. ATP-dependent recruitment, survival and differentiation of dendritic cell precursors in the tumor bed after anticancer chemotherapy. Oncoimmunology. (2013) 2:e24568. doi: 10.4161/onci.24568

56. Aymeric L. Tumor cell death and ATP release prime dendritic cells and efficient anticancer immunity. Cancer Res. (2010) 70:855-8. doi: 10.1158/0008-5472.CAN-09-3566

57. Gebremeskel S. Concepts and mechanisms underlying chemotherapy induced immunogenic cell death: impact on clinical studies and considerations for combined therapies. Oncotarget. (2015) 6:41600-19. doi: $10.18632 /$ oncotarget.6113

58. Showalter A, Limaye A, Oyer JL, Igarashi R, Kittipatarin C, Copik $\mathrm{AJ}$, et al. Cytokines in immunogenic cell death: applications for cancer immunotherapy. Cytokine. (2017) 97:123-32. doi: 10.1016/j.cyto.2017.05.024

59. Fucikova J, Kasikova L, Truxova I, Laco J, Skapa P, Ryska A, et al. Relevance of the chaperone-like protein calreticulin for the biological behavior and clinical outcome of cancer. Immunol Lett. (2018) 193:25-34. doi: 10.1016/j.imlet.2017.11.006

60. Fucikova J, Truxova I, Hensler M, Becht E, Kasikova L, Moserova I, et al. Calreticulin exposure by malignant blasts correlates with robust anticancer immunity and improved clinical outcome in AML patients. Blood. (2016) 128:3113-24. doi: 10.1182/blood-2016-08-731737

61. Wemeau M, Kepp O, Tesnière A, Panaretakis T, Flament C, De Botton S, et al. Calreticulin exposure on malignant blasts predicts a cellular anticancer immune response in patients with acute myeloid leukemia. Cell Death Dis. (2010) 1:e104. doi: 10.1038/cddis.2010.82

62. Fredly H, Ersvær E, Gjertsen BT, Bruserud O. Immunogenic apoptosis in human acute myeloid leukemia (AML): primary human AML cells expose calreticulin and release heat shock protein (HSP) 70 and HSP90 during apoptosis. Oncol Rep. (2011) 25:1549-56. doi: 10.3892/or.2011.1229

63. Galluzzi L, Senovilla L, Zitvogel L, Kroemer G. The secret al.y: immunostimulation by anticancer drugs. Nat Rev Drug Discov. (2012) 11:215-33. doi: 10.1038/nrd3626

64. Vanneman M, Dranoff G. Combining immunotherapy and targeted therapies in cancer treatment. Nat Rev Cancer. (2012) 12:237-51. doi: $10.1038 / \operatorname{nrc} 3237$
65. Sukkurwala AQ, Adjemian S, Senovilla L, Michaud M, Spaggiari S, Vacchelli E, et al. Screening of novel immunogenic cell death inducers within the NCI Mechanistic Diversity Set. Oncoimmunology. (2014) 3:e28473. doi: $10.4161 /$ onci.28473

66. van der Most RG, Currie AJ, Cleaver AL, Salmons J, Nowak AK, Mahendran S, et al. Cyclophosphamide chemotherapy sensitizes tumor cells to TRAIL-dependent CD8 T cell-mediated immune attack resulting in suppression of tumor growth. PLoS ONE. (2009) 4:e6982. doi: 10.1371/journal.pone.0006982

67. Menger L, Vacchelli E, Adjemian S, Martins I, Ma Y, Shen S, et al. Cardiac glycosides exert anticancer effects by inducing immunogenic cell death. Sci Transl Med. (2012) 4:143ra99. doi: 10.1126/scitranslmed.3003807

68. Zitvogel L, Galluzzi L, Smyth MJ, Kroemer G. Mechanism of action of conventional and targeted anticancer therapies: reinstating immunosurveillance. Immunity. (2013) 39:74-88. doi: 10.1016/j.immuni.2013.06.014

69. Chen G, Emens LA. Chemoimmunotherapy: reengineering tumor immunity. Cancer Immunol Immunother. (2013) 62:203-16. doi: $10.1007 / \mathrm{s} 00262-012-1388-0$

70. Liu WM, Fowler DW, Smith P, Dalgleish AG. Pre-treatment with chemotherapy can enhance the antigenicity and immunogenicity of tumours by promoting adaptive immune responses. Br J Cancer. (2010) 102:115-23. doi: $10.1038 /$ sj.bjc. 6605465

71. Frederick DT, Piris A, Cogdill AP, Cooper ZA, Lezcano C, Ferrone $\mathrm{CR}$, et al. BRAF inhibition is associated with enhanced melanoma antigen expression and a more favorable tumor microenvironment in patients with metastatic melanoma. Clin Cancer Res. (2013) 19:1225-31. doi: 10.1158/1078-0432.CCR-12-1630

72. Sharma A, Bode B, Wenger RH, Lehmann K, Sartori AA, Moch H, et al. $\gamma$-Radiation promotes immunological recognition of cancer cells through increased expression of cancer-testis antigens in vitro and in vivo. PLOS ONE. (2011) 6:e28217. doi: 10.1371/journal.pone.0028217

73. Yamazaki T, Hannani D, Poirier-Colame V, Ladoire S, Locher C, Sistigu A, et al. Defective immunogenic cell death of HMGB1-deficient tumors: compensatory therapy with TLR4 agonists. Cell Death Differ. (2014) 21:6978. doi: $10.1038 /$ cdd. 2013.72

74. Ramakrishnan R, Assudani D, Nagaraj S, Hunter T, Cho HI, Antonia S, et al. Chemotherapy enhances tumor cell susceptibility to CTL-mediated killing during cancer immunotherapy in mice. J Clin Invest. (2010) 120:1111-24. doi: 10.1172/JCI40269

75. Ruffell B, Au A, Rugo HS, Esserman LJ, Hwang ES, Coussens LM. Leukocyte composition of human breast cancer. Proc Natl Acad Sci USA. (2012) 109:2796-801. doi: 10.1073/pnas.1104303108

76. Rusakiewicz S, Semeraro M, Sarabi M, Desbois M, Locher C, Mendez $\mathrm{R}$, et al. Immune infiltrates are prognostic factors in localized gastrointestinal stromal tumors. Cancer Res. (2013) 73:3499-510. doi: 10.1158/0008-5472.CAN-13-0371

77. Catellani S, Pierri I, Gobbi M, Poggi A, Zocchi MR. Imatinib treatment induces $\mathrm{CD}^{+} \mathrm{B}$ lymphocytes and IgM natural antibodies with anti-leukemic reactivity in patients with chronic myelogenous leukemia. PLoS ONE. (2011) 6:e18925. doi: 10.1371/journal.pone.0018925

78. Zappasodi R, Pupa SM, Ghedini GC, Bongarzone I, Magni M, Cabras AD, et al. Improved clinical outcome in indolent B-cell lymphoma patients vaccinated with autologous tumor cells experiencing immunogenic death. Cancer Res. (2010) 70:9062-72. doi: 10.1158/0008-5472.CAN-10-1825

79. Fucikova J, Becht E, Iribarren K, Goc J, Remark R, Damotte D, et al. Calreticulin expression in human non-small cell lung cancers correlates with increased accumulation of antitumor immune cells and favorable prognosis. Cancer Res. (2016) 76:1746-56. doi: 10.1158/0008-5472.CAN-15-1142

80. Peng RQ, Chen YB, Ding Y, Zhang R, Zhang X, Yu XJ, et al. Expression of calreticulin is associated with infiltration of T-cells in stage IIIB colon cancer. World J Gastroenterol. (2010) 16:2428-34. doi: 10.3748/wjg.v16.i19.2428

81. Vaksman O, Davidson B, Tropé C, Reich, R. Calreticulin expression is reduced in high-grade ovarian serous carcinoma effusions compared with primary tumors and solid metastases. Hum Pathol. (2013) 44:2677-83. doi: 10.1016/j.humpath.2013.07.009

82. Isidori A, Salvestrini V, Ciciarello M, Loscocco F, Visani G, Parisi S, et al. The role of the immunosuppressive microenvironment in acute myeloid 
leukemia development and treatment. Expert Rev Hematol. (2014) 7:807-18. doi: 10.1586/17474086.2014.958464

83. Hobo W, Hutten TJA, Schaap NPM, Dolstra H. Immune checkpoint molecules in acute myeloid leukaemia: managing the double-edged sword. Br J Haematol. (2018) 181:38-53. doi: 10.1111/bjh.15078

84. Assi R, Kantarjian H, Ravandi F, Daver N. Immune therapies in acute myeloid leukemia: a focus on monoclonal antibodies and immune checkpoint inhibitors. Curr Opin Hematol. (2018) 25:136-45. doi: 10.1097/MOH.0000000000000401

85. Johnson TS, Mcgaha T, Munn DH. Chemo-immunotherapy: role of indoleamine 2,3-dioxygenase in defining immunogenic versus tolerogenic cell death in the tumor microenvironment. Adv Exp Med Biol. (2017) 1036:91-104. doi: 10.1007/978-3-319-67577-0_7

86. Cervenka I, Agudelo LZ, Ruas JL. Kynurenines: Tryptophan's metabolites in exercise, inflammation, and mental health. Science. (2017) 357:eaaf9794. doi: 10.1126/science.aaf9794

87. LaFleur MW, Muroyama Y, Drake CG, Sharpe AH. Inhibitors of the PD-1 pathway in tumor therapy. J Immunol. (2018) 200:375-83. doi: 10.4049/jimmunol.1701044

88. Berthon C, Driss V, Liu J, Kuranda K, Leleu X, Jouy N, et al. In acute myeloid leukemia, B7-H1 (PD-L1) protection of blasts from cytotoxic T cells is induced by TLR ligands and interferon-gamma and can be reversed using MEK inhibitors. Cancer Immunol Immunother. (2010) 59:1839-49. doi: 10.1007/s00262-010-0909-y

89. Zhou Q. Program death-1 signaling and regulatory T cells collaborate to resist the function of adoptively transferred cytotoxic $\mathrm{T}$ lymphocytes in advanced acute myeloid leukemia. Blood. (2010) 116:2484-93. doi: 10.1182/blood-2010-03-275446

90. Boddu P, Kantarjian H, Garcia-Manero G, Allison J, Sharma P, Daver N. The emerging role of immune checkpoint based approaches in AML and MDS. Leuk Lymphoma. (2018) 59:790-802. doi: 10.1080/10428194.2017.1344905

91. Alfayez M, Borthakur G. Checkpoint inhibitors and acute myelogenous leukemia: promises and challenges. Expert Rev Hematol. (2018) 11:373-89. doi: $10.1080 / 17474086.2018 .1459184$

92. Bewersdorf JP, Stahl M, Zeidan AM. Immune checkpoint-based therapy in myeloid malignancies: a promise yet to be fulfilled. Expert Rev Anticancer Ther. (2019) 19:393-404. doi: 10.1080/14737140.2019.1589374

93. Memarian A, Nourizadeh M, Masoumi F, Tabrizi M, Emami AH, Alimoghaddam K, et al. Upregulation of CD200 is associated with Foxp $3^{+}$ regulatory $\mathrm{T}$ cell expansion and disease progression in acute myeloid leukemia. Tumour Biol. (2013) 34:531-42. doi: 10.1007/s13277-012-0578-x

94. Coles SJ, Wang EC, Man S, Hills RK, Burnett AK, Tonks A, et al. CD200 expression suppresses natural killer cell function and directly inhibits patient anti-tumor response in acute myeloid leukemia. Leukemia. (2011) 25:792-9. doi: 10.1038/leu.2011.1

95. Coles SJ, Hills RK, Wang EC, Burnett AK, Man S, Darley RL, et al. Expression of CD200 on AML blasts directly suppresses memory T-cell function. Leukemia. (2012) 26:2148-51. doi: 10.1038/leu.2012.77

96. Rygiel TP, Meyaard L. CD200R signaling in tumor tolerance and inflammation: a tricky balance. Curr Opin Immunol. (2012) 24:233-8. doi: 10.1016/j.coi.2012.01.002

97. Lichtenegger FS, Rothe M, Schnorfeil FM, Deiser K, Krupka C, Augsberger C, et al. Targeting LAG-3 and PD-1 to enhance T cell activation by antigenpresenting cells. Front Immunol 9:385. doi: 10.3389/fimmu.2018.00385

98. Berrien-Elliott MM, Jackson SR, Meyer JM, Rouskey CJ, Nguyen TL, Yagita $\mathrm{H}$, et al. Durable adoptive immunotherapy for leukemia produced by manipulation of multiple regulatory pathways of $\mathrm{CD}^{+} \mathrm{T}$-cell tolerance. Cancer Res. (2013) 73:605-16. doi: 10.1158/0008-5472.CAN-12-2179
99. Gonçalves Silva I, Yasinska IM, Sakhnevych SS, Fiedler W, Wellbrock J, Bardelli $M$, et al. The tim-3-galectin-9 secretory pathway is involved in the immune escape of human acute myeloid leukemia cells. EBioMedicine. (2017) 22:44-57. doi: 10.1016/j.ebiom.2017.07.018

100. Kong Y, Zhang J, Claxton DF, Ehmann WC, Rybka WB, Zhu L, et al. PD1(hi)TIM-3(+) T cells associate with and predict leukemia relapse in AML patients post allogeneic stem cell transplantation. Blood Cancer J. (2015) 5:e330. doi: 10.1038/bcj.2015.58

101. Gao L, Yu S, Zhang X. Hypothesis: tim-3/galectin-9, a new pathway for leukemia stem cells survival by promoting expansion of myeloid-derived suppressor cells and differentiating into tumor-associated macrophages. Cell Biochem Biophys. (2014) 70:273-7. doi: 10.1007/s12013-014-9900-0

102. Li C, Chen X, Yu X, Zhu Y, Ma C, Xia R, et al. Tim-3 is highly expressed in $\mathrm{T}$ cells in acute myeloid leukemia and associated with clinicopathological prognostic stratification. Int J Clin Exp Pathol. (2014) 7:6880-8.

103. Curti A, Trabanelli S, Onofri C, Aluigi M, Salvestrini V, Ocadlikova D, et al. Indoleamine 2,3-dioxygenase-expressing leukemic dendritic cells impair a leukemia-specific immune response by inducing potent $\mathrm{T}$ regulatory cells. Haematologica. (2010) 95:2022-30. doi: 10.3324/haematol.2010.025924

104. Curti A. Acute myeloid leukemia cells constitutively express the immunoregulatory enzyme indoleamine 2,3-dioxygenase. Leukemia. (2007) 21:353-5. doi: 10.1038/sj.leu.2404485

105. Curti A. Modulation of tryptophan catabolism by human leukemic cells results in the conversion of $\mathrm{CD} 25^{-}$into $\mathrm{CD} 25^{+} \mathrm{T}$ regulatory cells. Blood. (2007) 109:2871-7. doi: 10.1182/blood-2006-07-036863

106. Lecciso M, Ocadlikova D, Sangaletti S, Trabanelli S, De Marchi E, Orioli E, et al. ATP release from chemotherapy-treated dying leukemia cells elicits an immune suppressive effect by increasing regulatory $\mathrm{T}$ cells and tolerogenic dendritic cells. Front Immunol. (2017) 8:1918. doi: 10.3389/fimmu.2017.01918

107. Bugaut $H$, Bruchard $M$, Berger $H$, Derangère V, Odoul L, Euvrard R, et al. Bleomycin exerts ambivalent antitumor immune effect by triggering both immunogenic cell death and proliferation of regulatory T cells. PLOS ONE. (2013) 8:e65181. doi: 10.1371/journal.pone.0065181

108. Kanakry CG, Hess AD, Gocke CD, Thoburn C, Kos F, Meyer C, et al. Early lymphocyte recovery after intensive timed sequential chemotherapy for acute myelogenous leukemia: peripheral oligoclonal expansion of regulatory $\mathrm{T}$ cells. Blood. (2011) 117:608-17. doi: 10.1182/blood-2010-04-277939

109. Yang W, Xu Y. Clinical significance of Treg cell frequency in acute myeloid leukemia. Int J Hematol. (2013) 98:558-62. doi: 10.1007/s12185-013-1 436-3

110. Wang $M$, Zhang $C$, Tian $T$, Zhang $T$, Wang $R$, Han $F$, et al. Increased regulatory $\mathrm{T}$ cells in peripheral blood of acute myeloid leukemia patients rely on tumor necrosis factor (TNF)- $\alpha$-TNF receptor2 pathway. Front Immunol. (2018) 9:1274. doi: 10.3389/fimmu.2018. 01274

Conflict of Interest: The authors declare that the research was conducted in the absence of any commercial or financial relationships that could be construed as a potential conflict of interest.

Copyright $\odot 2019$ Ocadlikova, Lecciso, Isidori, Loscocco, Visani, Amadori, Cavo and Curti. This is an open-access article distributed under the terms of the Creative Commons Attribution License (CC BY). The use, distribution or reproduction in other forums is permitted, provided the original author(s) and the copyright owner(s) are credited and that the original publication in this journal is cited, in accordance with accepted academic practice. No use, distribution or reproduction is permitted which does not comply with these terms. 